\title{
ASSESSMENT OF HARDNESS, FLEXURAL MODULUS, AND BOND STRENGTH OF ACRYLIC DENTURE BASES FABRICATED BY 3D DIGITAL METHODS
}

\author{
Aya Mohamed Fawzy Hafez*, Ramy Abdallah Abdelrahim** \\ and Bassem Mohsen Abdel Hameed*
}

\begin{abstract}
Objectives: The inferior mechanical properties and the clinical failure of the denture bases could be related to their processing technique and the type of resin used during fabrication. Therefore, this study aimed to evaluate and compare the effect of the processing technique on the hardness, flexural modulus, and bond strength of the different denture base resins.
\end{abstract}

Materials and Methods: Three processing techniques were used in the present study to fabricate the tested samples; compression-molded fabrication method "control group", and two different three-dimensional (3D) fabrication methods (CAD/CAM milled "subtractive", and 3D printed "additive"). The samples used in this study fabricated with different dimensions according to the type of test (hardness, flexural modulus, and shear bond strength).

Results: The results of hardness and flexural modulus revealed that; the CAD/CAM milled samples showed statistically significant higher hardness and flexural modulus values followed by the conventional compression molded and 3D printed respectively. While the results of shear bond strength showed no statistically significant difference among the three different processing methods.

Conclusion: the processing technology has a significant effect on the hardness and flexural modulus of the material. While there is no effect to the fabrication technique on the teeth bond strength.

KEYWORDS: Bond strength, Denture base, Digital fabrication, Flexural modulus, Hardness

Lecturer of Removable Prosthodontics, Faculty of Oral and Dental Medicine, Future University in Egypt.

** Associated Professor of Dental Biomaterial, Faculty of Faculty of Dentistry, Al-Azhar University. 


\section{INTRODUCTION}

Fabrication of the acrylic denture bases from heat-cured polymethyl methacrylate (PMMA) by compression molded technique still the most popular choice for clinicians in the dental office ${ }^{(1)}$. The popularity of this fabrication method in denture bases construction is gained due to its simplicity, as well as this technique needs only simple processing equipment ${ }^{(2)}$. Moreover, its low cost, ease of repair, relative higher mechanical properties, low density, and acceptable esthetic favored their popularity over other processing techniques ${ }^{(2,3)}$.

However, the recent fabrication methods were introduced in the dental practice such as the injection-molded method and the revolutionized computer-aided design and computer-aided manufacturing (CAD/CAM) digital method ${ }^{(4,5)}$. The digital method enables automated fabrication of 3D denture base by the utilization of different materials with different mechanical and physical properties ${ }^{(6,7)}$. The CAD/CAM digital fabrication technique utilizes the fabrication of the denture base by either milling "subtractive" or three-dimensional (3D) printing "additive" methods ${ }^{(8,9)}$.

The fabrication of denture bases by digital methods has different advantages such as the production of faster denture with lesser time and fewer processing phases ${ }^{(6,10)}$. Moreover, digital methods were developed to overcome the possible processing errors which companied by the usual compression-molded technique ${ }^{(10)}$. Digital methods allow the fabrication of a denture with the artificial teeth in one block or provide only the denture base as a separate piece with the ability to attach prefabricated artificial teeth with an appropriate adhesive ${ }^{(6,8)}$.

Manufacturers claim that digital dentures have improved physicomechanical properties compared to conventional dentures ${ }^{(11,12)}$. Moreover, it was claimed that the material used in the manufacturing of digital denture appears to contain less residual monomer than the conventionally processed one which allows better surface properties ${ }^{(13,14)}$.
Bond failures at the interface between the denture base and the artificial teeth still a common clinical problem in the dental office ${ }^{(15)}$. Moreover, the transverse strength and hardness tests are commonly used to compare the denture bases ${ }^{(8)}$. Therefore, this study aimed to examine the surface hardness, flexural modulus, and bond strength, of different denture base fabricated with CAD/CAM and 3D printing digital technologies, and compare them with conventional denture bases.

\section{MATERIALS AND METHODS}

Three different denture base materials were selected for this study; pre-polymerized PMMA plates (SPEC 98x20 shade 2S Monolayer), photopolymerized monomer resin (Nextdent base, the Netherlands), and heat-polymerized PMMA (Vertex-Dental BV. Headquarters, Netherlands) as a "control group". The three different materials were processed by three different methods; CAD/CAM milled "subtractive", 3D printing "additive", and compression-molded respectively.

Sample size: The calculations of sample size were performed according to Saavedra et al (16) using SPSS software, version 20. It is estimated 6 samples per group with a $95 \%$ confidence interval level and a standard error of 5\%.

Sample grouping: The total of 54 samples were used in the present study and categorized into three main groups $(n=18)$ according to the type of the material used, then each main group was further subdivided into three subgroups $(n=6)$ according to the test (hardness, flexural modulus, and bond strength).

\section{Sample fabrication:}

\section{Compression mold PMMA samples:}

A template of wax (Green wax for burn out) were made with dimension according to each test with the aid of a 3D printing unit (EPAX 3D, North Carolina, USA). The wax templates were then invested with gypsum in the conventional metal flask. For each wax template, the gypsum was poured into the flask 
then the wax template was coated with a separating medium and placed inside the gypsum in the lower half of the metal flask. After that, the flask was filled with gypsum and closed. After setting of gypsum, the flask was opened and the wax was eliminated by using of hot water bath. The formed mold was painted with a separating medium and the heatpolymerized PMMA resin was processed according to the manufacture instructions ${ }^{(8)}$.

\section{CAD/CAM milled samples:}

A 3D cylinder with dimensions $6 \mathrm{~mm} \times 8 \mathrm{~mm}$ was virtually designed using CAD software (Blender software) and saved as a standard tessellation language (STL) file format. Then, STL files were exported to the milling machine be used for fabricating the milled samples from pre-polymerized PMMA blocks (SPEC 98x20 shade 2S Monolayer) with CAD/CAM milling machine (Dentsply Sirona in Lab MC X5, Germany) ${ }^{(6,11)}$ (Figure 1).

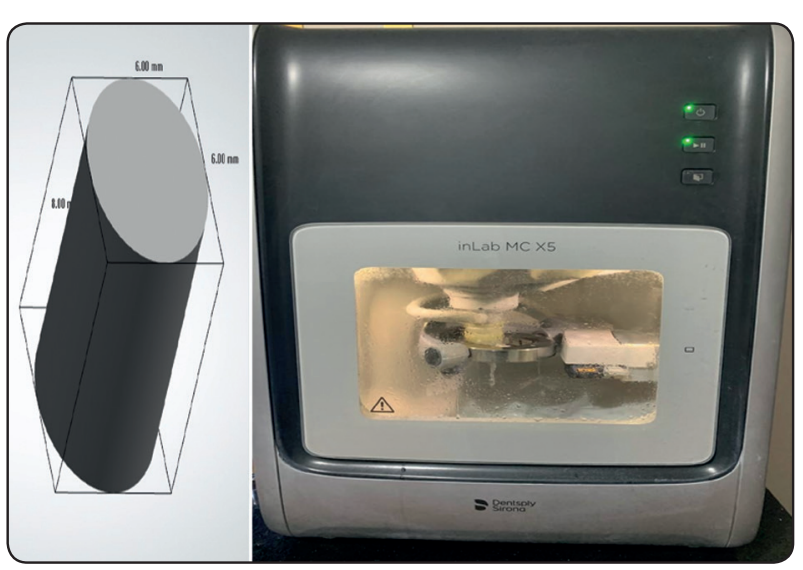

Fig. (1) The CAD/CAM milling machine.

3D printed samples: The STL files used in the fabrication of the milled samples were also used in the fabrication of the 3D printed samples. The nozzle of the 3D printing unit (EPAX 3D, North Carolina, USA) was used to pour the liquid monomer into layers (Figure 2). Then the printed rods were exposed to a digital ultrasonic cleaner to remove any residues. After that, the printed rods were finally cured with a special ultraviolet light curing box (Bredent, Bre. Lux power unit 2, lead full range system) for 15 minutes according to manufacturer instructions ${ }^{(8)}$. After manufacturing, all samples were finished and polished using tungsten carbide acrylic burs followed by metallic grinding sandpapers (500, 1000, and 1200 grit), and finally, all samples were further polished using polishing pumice ${ }^{(8,11)}$.

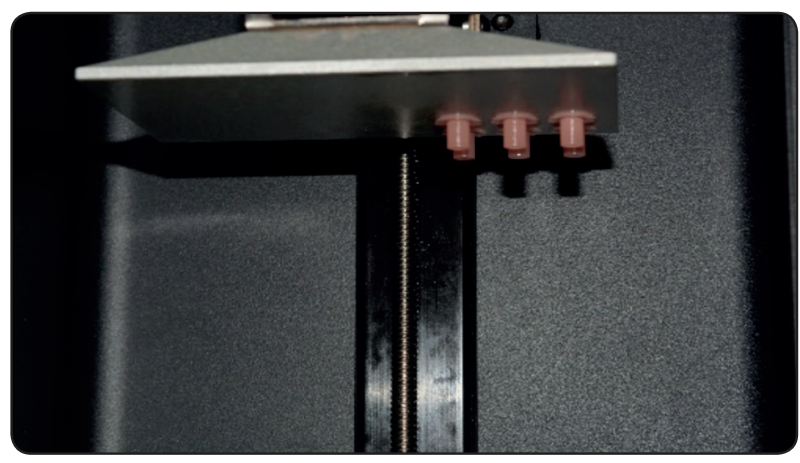

Fig. (2) The 3D printing machine.

\section{Hardness test:}

A rectangular-shaped sample of each material with the dimensions of $20 \times 6 \times 2 \mathrm{~mm}$ was used for the Vickers hardness test (Tukon 1102 Wilson hardness tester Buehler Germany). The load of 200 grams was applied smoothly, without impact, forcing the indenter into the surface of the tested sample. The indenter is held in place for 15 seconds (Figure 3). After removal of the load, the indentation was focused with the magnifying eyepiece, and the two impression diagonals are measured, usually to the nearest $0.1 \mu \mathrm{m}$, and averaged. The Vickers hardness number (HV) was calculated using the following equation: $\mathrm{HV}=1854.4 \mathrm{~L} / \mathrm{d}^{2}$, where $\mathrm{L}$; the applied load $(\mathrm{kg})$, and, d; the average diagonal $(\mathrm{mm}){ }^{(17)}$.

\section{Flexural modulus:}

A rectangular-shaped sample of each material with a dimension of $65 \times 10 \times 3 \mathrm{~mm}$ was used for the 3 points bending test. The three-point bending test were used to tests the flexural modulus via using a universal testing machine (Instron 3345, England). 


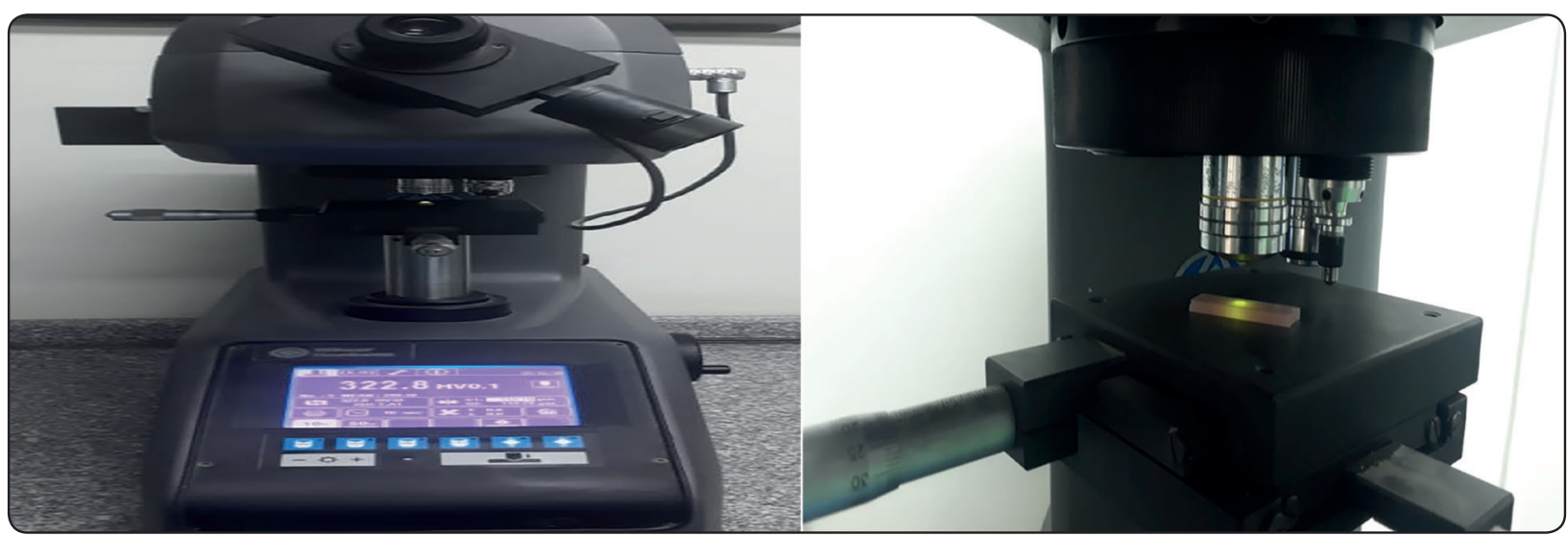

Fig. (3) Hardness test.

Before testing, all samples were immersed in a distilled water bath at $37^{\circ} \mathrm{C}$ for 24 hours. Then, the samples were removed from the water bath and hold horizontally and supported by two supported centers with the distance between them of $50-\mathrm{mm}$ on the base of the testing machine. The load cell of $500-\mathrm{kg}$ with a crosshead speed of $5 \pm 1 \mathrm{~mm} / \mathrm{min}$ was used to apply load on the midpoint of each sample until fracture ${ }^{(11,18)}$ (Figure 4). The flexural modulus of each sample was measured according to the following formula: $E=\mathrm{PL}^{3} / 4 \mathrm{bh}^{3} \mathrm{~d}$, where; $E$; flexural modulus (MPa), $\mathrm{P}$; load at fracture $(\mathrm{N})$, $\mathrm{L}$; span length of sample $(\mathrm{mm}), \mathrm{b}$; sample width $(\mathrm{mm}), \mathrm{h}$; thicknesses of the sample $(\mathrm{mm})$ and $\mathrm{d}$; deflection $(\mathrm{mm})^{(18)}$.

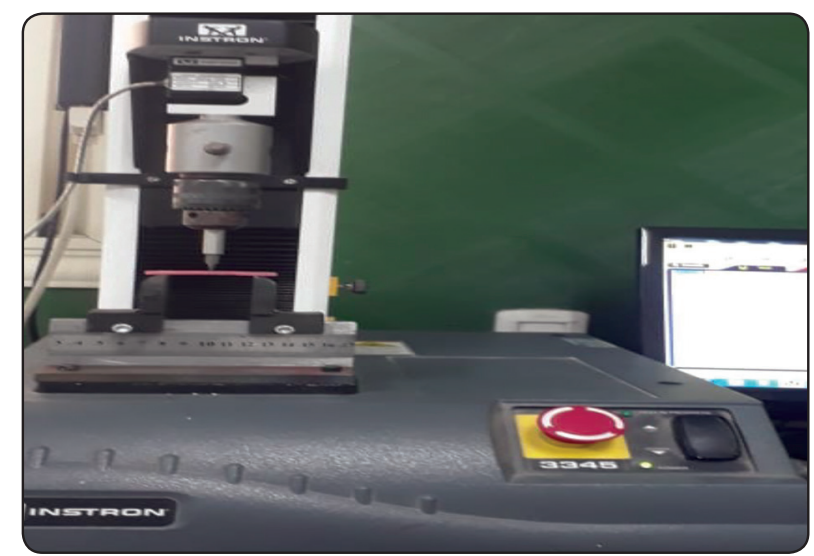

Fig. (4) Flexural modulus test.

\section{Bond Strength:}

A rod shape samples with dimensions of $6 \times 8 \mathrm{~mm}$ of each resin material were used to bond the acrylic tooth to their ridge-like surface. Before cementation, the ridge-like surface of the denture teeth was flattened and polished with diamond finishing stone and sand-paper disk ${ }^{(6)}$. Then, the teeth in all tested groups were cemented with $\mathrm{CAD} / \mathrm{CAM}$ milled and 3D printed resin rods by adhesive bond (Visio. Link, Bredent) and auto-polymerized resin cement (Bredent, DTK- Kleber) (Figure 5).

The shear bond strength (SBS) testing was carried out on a universal testing machine at the tooth resin interface by a chisel-like jig connected to a load cell of $500-\mathrm{kg}$ with a crosshead speed of $0.5 \mathrm{~mm} / \mathrm{min}$ until failure ${ }^{(6,15)}$ (Figure 6). The shear bond strength was calculated according to the following equation; SBS $(\mathrm{MPa})=$ force to failure $(\mathrm{N}) /$ bonding area $\left(\mathrm{mm}^{2}\right)$.

\section{Statistical analysis:}

All data were collected, tabulated, and statically analyzed via SPSS version 20 using one-way ANOVA, and the comparison among the groups was performed using a posthoc Tukey (HSD) test. 


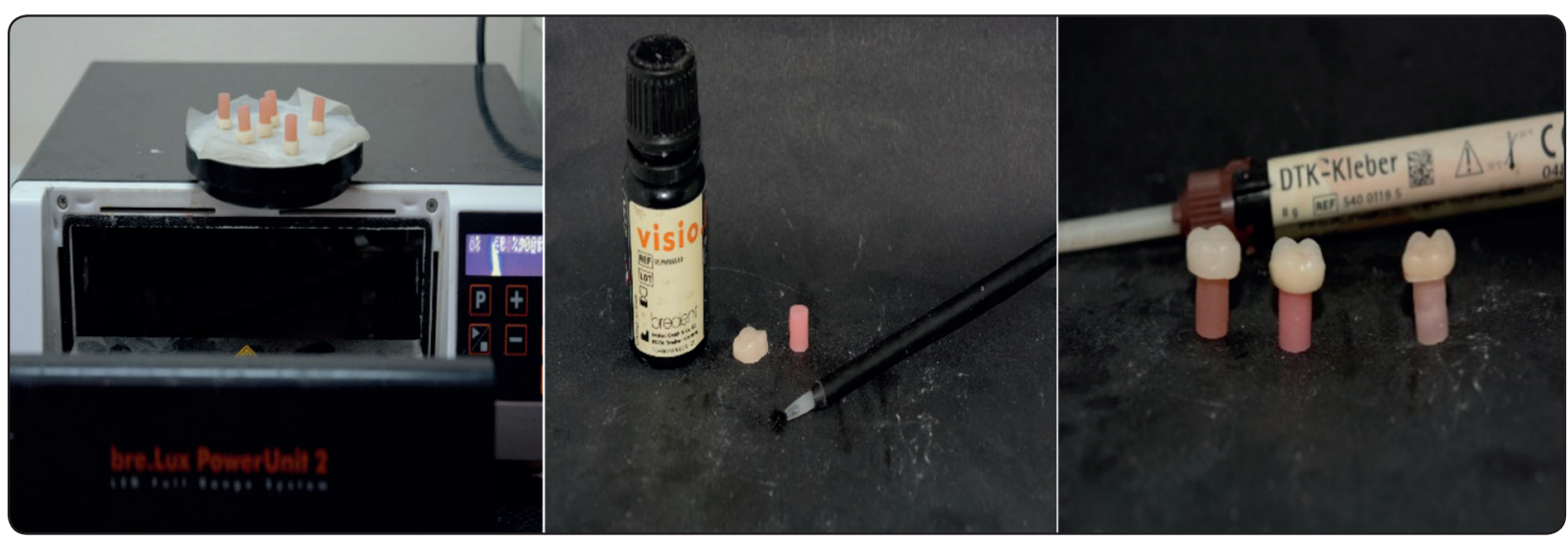

Fig. (5) Cementation of acrylic teeth to the rod shape samples.

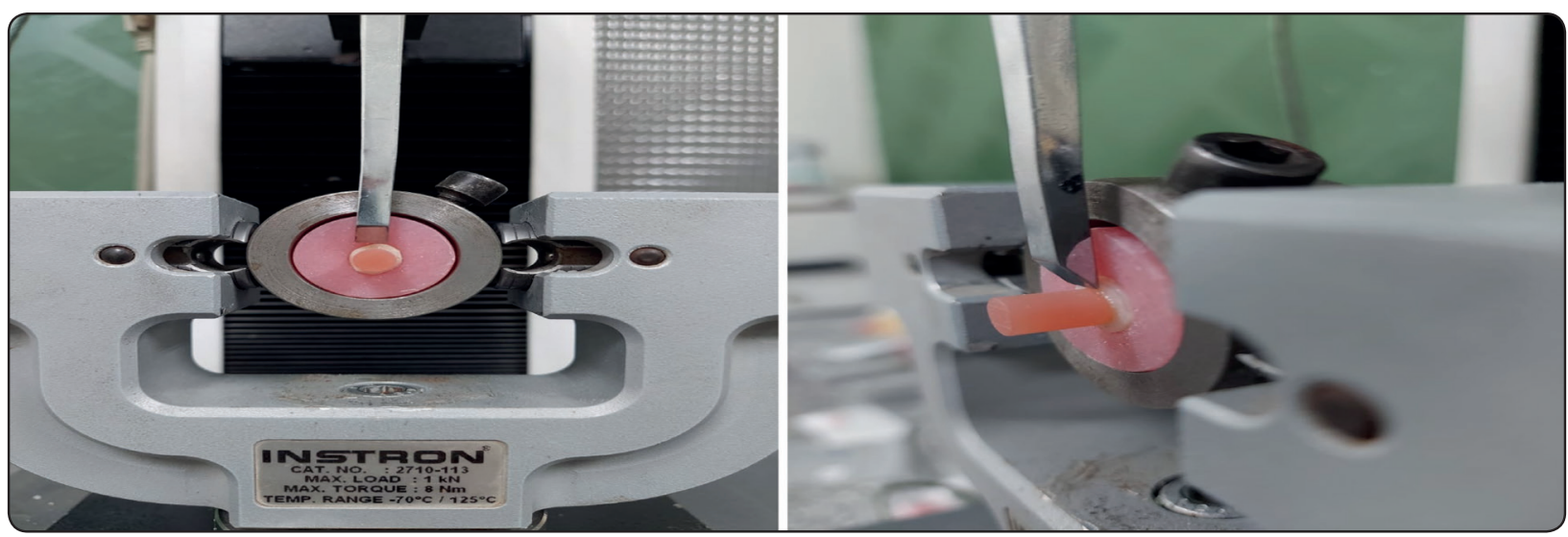

Fig. (6) Shear bond strength test.

\section{RESULTS}

\section{Hardness}

The results of the surface hardness test revealed a statistically significant difference between the tested groups. The CAD/CAM milled group showed the higher mean hardness results followed by the conventional heat polymerized. While the lower mean hardness was recorded with the 3D printed group (Table 1).

The Tukey's HSD test results among the groups revealed a statistically significant difference between the hardness of the conventional and 3D print samples with a $p$-value of $(p=0.00015)$, and between $\mathrm{CAD} / \mathrm{CAM}$ and conventional samples, as well as between CAD/CAM and 3D print with a $p$-value of $(p=0.00048),(p=0.00000)$ respectively.
TABLE (1) Hardness between different groups

\begin{tabular}{|c|c|c|c|c|}
\hline Variable & $\begin{array}{c}\text { Mean } \\
(\mathrm{MPa})\end{array}$ & $\mathrm{SD}$ & $\begin{array}{c}F \text {-ratio } \\
\text { value }\end{array}$ & $p$-value \\
\cline { 1 - 3 } Compression-molded & 23.12 & 0.4324 & & \\
\cline { 1 - 3 } CAD/CAM milled & 30.62 & 3.4781 & 65.25168 & $<0.00001^{*}$ \\
\cline { 1 - 3 } 3D print & 14.6 & 1.5764 & & \\
\hline
\end{tabular}

*The result is significant at $p<0.05$.

\section{Flexural modulus:}

The flexural modulus results showed a statistically significant difference between the tested groups. The CAD/CAM milled samples showed the higher flexural modulus followed by the conventional PMMA samples, while, the lower flexural modulus value recorded with the $3 \mathrm{D}$ printed resin (Table 2). 
TABLE (2) Flexural modulus between different groups

\begin{tabular}{|c|c|c|c|c|}
\hline Variable & $\begin{array}{c}\text { Mean } \\
(\mathrm{GPa})\end{array}$ & $\mathrm{SD}$ & $\begin{array}{c}F \text {-ratio } \\
\text { value }\end{array}$ & $p$-value \\
\cline { 1 - 3 } Compression-molded & 3.062 .2919 & 0.182 & & \\
\cline { 1 - 3 } CAD/CAM milled & 3.253 .3972 & 0.052 & \multirow{2}{*}{900.06691} & $<0.00001^{*}$ \\
\cline { 1 - 3 } 3D print & 0.582 .3164 & 0.029 & & \\
\hline
\end{tabular}

*The result is significant at $p<0.05$.

Tukey's HSD test results among the tested groups showed a statistically significant difference between $\mathrm{CAD} / \mathrm{CAM}$ and conventional with a $p$-value of ( $p=0.04555)$. Moreover, there was a statistically significant difference between conventional and 3D print as well as between CAD/CAM and 3D print with $P$-value of $(p=0.00000)$ and $(p=0.00000)$ respectively.

\section{Bond strength:}

The results of the shear bond strength test showed non-statically significant difference among the three tested groups (Table 3). The CAD/CAM milled groups showed the lower shear bond strength followed by the compression-molded group. While the 3D printed group showed higher shear bond strength.

TABLE (3) Shear bond strength between different groups

\begin{tabular}{|c|c|c|c|c|}
\hline Variable & Mean & SD & $\begin{array}{c}F \text {-ratio } \\
\text { value }\end{array}$ & $p$-value \\
\cline { 1 - 3 } Compression-molded & 7.0844 & 1.6317 & & \\
\cline { 1 - 3 } CAD/CAM milled & 6.9154 & 1.9182 & \multirow{2}{*}{ 2.07246 } & \multirow{2}{*}{0.154877} \\
\cline { 1 - 3 } 3D print & 8.9739 & 2.6556 & & \\
\hline
\end{tabular}

$*$ The result is significant at $p<0.05$.

\section{DISCUSSION}

Poor mechanical properties of the denture bases are the most common cause of clinical failure ${ }^{(19)}$. Moreover, the bond failure between the artificial teeth and the denture base is another common cause for denture failure during service ${ }^{(6,15)}$. Clinically, there are various acrylic materials used in the construction of the denture base with various processing techniques ${ }^{(1-5)}$. Therefore, laboratory tests were used mainly to predict and compare the clinical performance of the denture base materials ${ }^{(20)}$.

The hardness of the resin denture base material is an important factor that determining the resistance to abrasion and hence surface roughness and microbial adhesion ${ }^{(8,20)}$. Moreover, the flexural modulus reflects the material's stiffness and rigidity as well as the ability of the material to equally distribute the forces to the underlying structures ${ }^{(11,21)}$. Findings related to the flexural strength of $\mathrm{CAD} / \mathrm{CAM}$ materials for denture base vary ${ }^{(22)}$.

In this study, the results of the CAD/CAM milled samples showed the statistically higher surface hardness and the flexural modulus mean value followed by the conventional heat-polymerized denture base samples, and the 3D-printed samples showed the lower mean value. This may be due to the difference in the processing technique and the manufacturing of the materials ${ }^{(8)}$. Where, the CAD/CAM milled samples are manufactured from condensed and fully polymerized PMMA blocks, with lower or free monomers ${ }^{(8,23)}$.

On the other hand, the processing of the heatpolymerized PMMA via conventional molded technique may result in a higher percentage of residual monomers which act as a plasticizer and decrease the hardness and rigidity of the material ${ }^{(20,24)}$. While the manufacturing of the denture base samples with the $3 \mathrm{D}$ printing technique with the use of photopolymerized monomers resulted in a higher number of residual monomers which resulted in inferior surface hardness and lower rigidity of the materials due to its "plasticizer effect" $(25,26)$. 
The shear bond strength between the acrylic teeth and the denture base could depend on the processing technique, the amount of the residual monomers, the fabrication method, the type of artificial teeth, and/or the composition of resin cement ${ }^{(6,27)}$. The insignificant shear bond strength results among the three different processing techniques in the present study may be due to the composition of resin cement used in the present study. Where, the used autopolymerized resin cement contains MMA monomer which resulted in good bond strength between the PMMA denture resins and acrylic teeth ${ }^{(15,28)}$.

Moreover, the 3D printed samples showed higher shear bond strength followed by the conventional heat-polymerized samples. This may be due to that the higher amount of the residual monomers in the 3D printed samples compared to the conventional heat-polymerized samples ${ }^{(6,15)}$. Where, the residual monomers able to penetrate from the denture base resin into the resin tooth matrix which resulted in proper bonding between the sample and the acrylic tooth, and hence, the increased amount of the residual monomer could increase bond strength ${ }^{(6,29)}$.

On the other hand, the heat-polymerized samples showed higher shear bond strength when compared with pre-polymerized CAD/CAM resin. This may be because of the chemical bonding between acrylic teeth and the conventional PMMA resin which resulted from the use of MMA-based resin cement in the present study ${ }^{(6,15,30)}$.

\section{CONCLUSION}

Within the limitation of this study, it was concluded that the processing technique had a significant effect on the hardness and flexural modulus of the resulted prosthesis. While the fabrication method did not affect the shear bond strength between the denture base and the acrylic teeth.

\section{REFERENCE}

1. Lee S, Hong S-J, Paek J, Pae A, Kwon K-R, Noh K. Comparing accuracy of denture bases fabricated by injection molding, CAD/CAM milling, and rapid prototyping method. J Adv Prosthodont 2019; 11:55-64.

2. Chintalacheruvu VK, Balraj RU, Putchala LS, Pachalla S. Evaluation of three different processing techniques in the fabrication of complete dentures. J Int Soc Prevent Communit Dent. 2017;7: S18-23.

3. Zafar MS. Prosthodontic applications of polymethyl methacrylate (PMMA): An update. Polymers. 2020; 12: 2299-332.

4. Kalberer N, Mehl A, Schimmel M, Müller F, Srinivasan M. CAD-CAM milled versus rapidly prototyped (3D-printed) complete dentures: An in vitro evaluation of trueness. JPD. 2019; 121;637-43.

5. Al Jabi LMZ, Al Essa HA, Ibrahim SK, Al Najjar RA. Evaluating the growth of candida Albicans on removable complete dentures bases manufactured using CAD/CAM designed metal (Co-Cr casted from milled wax patterns) and injection-molded resin. Int J Appl Dent Sc. 2020; 6: 474-79.

6. Han SY, Moon YH, Lee J. Shear bond strength between CAD/CAM denture base resin and denture artificial teeth when bonded with resin cement. J Adv Prosthodont. 2020; 12:251-58.

7. You S-M, You S-G, Lee B-II, Kim J-H. Evaluation of trueness in a denture base fabricated by using CAD-CAM systems and adaptation to the socketed surface of denture base: An in-vitro study. JPD. 2020; 139:27-32.

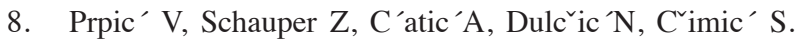
Comparison of mechanical properties of 3D-printed, $\mathrm{CAD} / \mathrm{CAM}$, and conventional denture base materials. JPD. 2020; 29:524-28.

9. Srinivasan M, Kalberer N, Naharro M, Marchand L, Lee H, Frauke Müller. CAD-CAM milled dentures: The Geneva protocols for digital dentures. JPD. 2020; 123:27-37.

10. Janeva NM, Kovacevska G, Elencevski S, Panchevska S, Mijoska A, Lazarevska B. Advantages of CAD/CAM versus conventional complete dentures - A review. Open Access Maced J Med Sci. 2018; 6: 1-4.

11. Al-Dwairi ZN, Tahboub KY, Baba NZ, Goodacre JC. A Comparison of the flexural and impact strengths and flexural modulus of CAD/CAM and conventional heatcured polymethyl methacrylate (PMMA). JPD. 2018; 29:1-9. 
12. Arslan M, Murat S, Alp G, Zaimoglu A. Evaluation of flexural strength and surface properties of pre-polymerized CAD/CAM PMMA-based polymers used for digital 3D complete dentures. Int J Comput Dent. 2018; 21:31-40.

13. Ayman AD. The residual monomer content and mechanical properties of CADICAM resins used in the fabrication of complete dentures as compared to heat-cured resins. Electr Physic. 2017; 9:4766-72.

14. Saad YM, Abdelhamid AM, ElShabrawy SM. Laboratory evaluation of pre-polymerized denture base material used for $\mathrm{CAD} / \mathrm{CAM}$ complete denture manufacturing. Alex Dent J. 2018; 43:94-101.

15. Yadav NS, Somkuwar S, Mishra SK, Hazari P, Chitumalla R, Pandey SK. Evaluation of bond strength of acrylic teeth to denture base using different polymerization techniques: A comparative study. J Int Oral Health. 2015; 7:54-56.

16. Saavedra G, Valandro LF, Leite FP, Amaral R, Özcan M, Bottino MA, et al. Bond strength of acrylic teeth to denture base resin after various surface conditioning methods before and after thermocycling. Int J Prosth. 2007; 20: 199-203.

17. Pacquet $\mathrm{W}$, Benoit $\mathrm{A}$, Hatège-Kimana $\mathrm{C}$, Wulfman $\mathrm{C}$. Mechanical Properties of CAD/CAM Denture Base Resins. Int J Prosthodont. 2019; 32:104-106.

18. Deste G, Durkan D, Oyar P. Evaluation of the Transverse Strength and Elastic Modulus of High Impact Denture Base Material. J Dent Mater Tech. 2020; 9: 107-15.

19. Steinmassl O, Offermanns V, Stöckl W, Dumfahrt H, Grunert I, Patricia-Anca Steinmassl P-A. In vitro analysis of the fracture resistance of CAD/CAM Denture base resins. Materials. 2018; 11:401-14.

20. Jafari P, Karimi VS, Amirian K, Tutunchian K, larijani M, Alhavaz A. Evaluation of beverages effect on the surface hardness and roughness of cad/cam and heat cure resin base. Int J Adv Sci Tech. 2010; 29: 3993-4002.

21. Puri G, Berzins DW, Dhuru VB. Effect of phosphate group addition on the properties of denture base resins. J Prosthet Dent. 2008; 100:302-308.

22. Ucar Y, Akova T, Aysan I. Mechanical properties of polyamide versus different PMMA denture base materials. J Prosthodont. 2012; 21:173-76.

23. Infante L, Yilmaz B, McGlumphy E. Fabricating complete dentures with CAD/CAM technology. J Prosthet Dent. 2014; 111:351-55.

24. Chang Y-H, Lee C-Y, Ming-Sung HSU, Je-Kang DU, Chen K-K, Ju-Hui WU. Effect of toothbrush/dentifrice abrasion on weight variation, surface roughness, surface morphology, and hardness of conventional and CAD/ CAM denture base materials. 2021; 40: 220-227.

25. Anadioti E, Musharbash L, Blatz MB. et al. 3D printed complete removable dental prostheses: A narrative review. BMC Oral Health. 2020; 20:343-48.

26. Tzeng J-J, Yang T-S, Lee W-F, Chen H, Chang H-M. Mechanical properties and biocompatibility of urethane acrylate-based 3D-Printed denture base resin. Polymers. 2021; 13: 822-26

27. Nakhaei M, Dashti H, Barazandeh R, Teimouri N. Shear Bond Strength of Acrylic Denture Teeth to PMMA and Polyamide Denture Base Materials. J Dent Mater Tech. 2018; 7: 19-24.

28. Della BA, Cantellia V, Britto VT, Collaresa FK, Stansbury JW. 3D printing restorative materials using a stereolithographic technique: A systematic review. Dent Mat. 2021; 336-50.

29. Zidan S, Silikas N, Haider J, Alhotan A, Jahantigh J, Yates J. Assessing tensile bond strength between denture teeth and nano-zirconia impregnated PMMA denture base. Int J Nanomedicine. 2020; 15:9611-25.

30. Gharebagh TG, Hamedirad F, Miruzadeh K. Comparison of bond strength of acrylic, composite, and nanocomposite artificial teeth to heat-cure acrylic denture base resin. Front Dent. 2019; 16:166-72. 